\title{
Position of Impacted Maxillary Central Incisor Influencing Spontaneous Eruption and Timing
}

\author{
Dr. Seema Diwan ${ }^{1}$,Dr.Navneet Jain ${ }^{2}$ \\ ${ }^{I} M D S$, FCFO (Fellowship in Craniofacial Orthodontics) University of Canterbury, New Zealand. \\ ${ }^{2}$ M.S,Associate professor Department of surgery, Doon Medical college,Dehradun
}

\begin{abstract}
:
OBJECTIVE: To evaluate the influence of the initial vertical position of impacted maxillary incisor on spontaneous eruption frequency and its timing after surgical removal of the supernumerary tooth.

Material And Methods: 44 patients with unilateral impaction of maxillary permanent central incisor with an average age of 10.5 years were studied for spontaneous eruption of impacted tooth. Orthopantomograms were taken of every patient. The time (in months) of spontaneous eruption was registered as a time from surgical removal of the supernumerary tooth till visible emergence of impacted central incisor.

Results: Statistically significant differences in the spontaneous eruption time were found between the groups with different initial vertical position of the impacted central maxillary incisor. The spontaneous eruption of impacted central incisors was registered in 30 (68\%) cases after removal of the supernumerary tooth. On the average, time of spontaneous eruption for the study group was 10.9 months.

Conclusion: Maxillary central incisor impacted at the projection level of the apical third of the contralateral completely erupted central maxillary incisor root, should be treated by the surgical-orthodontic approach, because spontaneous eruption is unlikely to expect.
\end{abstract}

\section{Introduction}

Delayed eruption of maxillary incisors requires monitoring or intervention when there is eruption of contralateral teeth that occurred greater than six months previously. Both central incisors remain unerupted and the lower incisors have erupted greater than one yearpreviously. There is deviation from the normal sequence of eruption (e.g. lateral incisors erupting prior to thecentral incisor [1,2]. The incidence of unerupted maxillary central incisor in the 5-12 year-old age group has been reported as $0.13 \%$ [3]. Eruption failure may occur if pathological obstructions, such as supernumerary teeth, odontomas, cysts, develop in the eruptive path of the incisor [4]. Supernumerary teeth and odontomas are the most common cause: 56-60\% of supernumerary teeth cause impaction of permanent incisors due to a direct obstruction for the eruption [5]. Eruption failure can also be caused by tooth malformation or dilacerations. Other possible causes of lack of eruption of maxillary incisors are: ectopic position of the tooth bud, non-vital orankylosed primary teeth, early extraction (or loss) of deciduous teeth, mucosal barriers in the path of eruption that acts as a physical barrier to eruption, endocrine abnormalities, bone disease [6].Impaction of maxillary permanent incisors is not a frequent case in dental practice, but its treatment is challenging because of their importance to facial esthetics. 56-60\% of premaxillary supernumerary teeth cause impaction of permanent incisors [7,8]due to a direct obstruction for the eruption, tipping of the adjacent teeth towards the place of the impacted tooth, narrowing of the dental arch, displacement of the permanent teeth bud, or malformations of the unerupted tooth root $[9,10,11]$. Spontaneous eruption of impacted maxillary incisors occurs in 54-76\% of cases when supernumerary tooth is removed and there is enough space in the dental arch $[12,13,14]$. However, research data indicate that the spontaneous eruption of impacted maxillary incisor may take up to 3 years and sometimes orthodontic treatment is necessary to achieve adequate alignment of the erupted tooth in the dental arch $[15,16,17,18]$. Nevertheless, in some instances, eliminating the cause of the maxillary incisor impaction by removing supernumerary tooth, would not lead to a spontaneous resolution of the problem. It is therefore necessary second surgical exposure of the unerupted tooth by removing any hard or soft tissue obstruction, placement of the attachment on the tooth crown and application of the directional traction by the orthodontic appliance $[7,19,20]$. But such extensive procedure on the soft tissue and underlying bone may have an impact on periodontal prognosis, poor gingival contour of the erupted teeth $[16,20,21]$. In clinical practice, the treatment of the impaction of permanent teeth caused by supernumerary teeth is frequently prolonged. This requires the setting of certain guidelines in the treatment of toothimpaction caused by supernumerary teeth. Spontaneous eruption of the impacted maxillary incisors there are no doubt has an advantage over its surgical-orthodontic treatment approach. But is it possible to predict spontaneous eruption of impacted maxillary incisor and its timing after removal of the supernumerary tooth? There is no clear answer yet, because a lot of factors, such as initial location and axial inclination of impacted teeth, lack of space in the dental arch and many others can influence the process $[16,17]$. 
The aim of present retrospective study was to evaluate the influence of the initial vertical position of impacted maxillary incisor on spontaneous eruption frequency and its timing after surgical removal of the supernumerary tooth.

\section{Material And Methods}

This retrospective study comprised of 44 patients with unilateral impaction of maxillary permanent central incisor with an average age 10.5 years, coming to Dental OPD of HIMS from 2010-14. The distribution of the patients according to their gender was the following: 29 boys (65.9\%) and 15 girls (34.0\%).

\section{Study Design:}

Type of the study: Observational

Sample size - Minimum number of subjects - 44

Selection of Subject:

Inclusion Criteria:

- Unilateral impaction of permanent upper central incisor because of supernumerary teeth;

- Space available or created by fixed or removable appliance for the impacted central incisor at least $7 \mathrm{~mm}$;

- Favorable axial inclination of impacted maxillary central incisor for spontaneous eruption;

- Incompleteroot formation of impacted maxillary central incisor;

- Good quality initial orthopantomograms and plaster casts available.

- Duration of waiting for the spontaneous eruption of impacted tooth was not less than 2 and half years after removal of supernumerary tooth

\section{Study Protocol:}

The vertical position of impacted permanent central incisors was evaluated on the orthopantomograms in relation to the contralaterally erupted central incisor. To determine initial vertical position of impacted tooth, the thirds of the root length of the erupted contra lateral central incisor were used. Three possible vertical positions of impacted incisor have been defined (Figure 1).

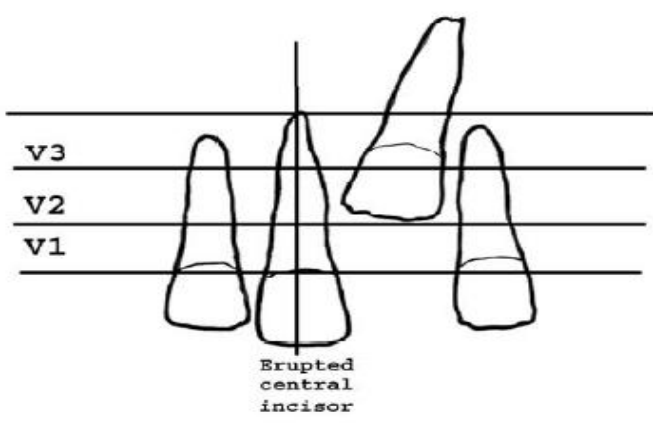

Fig 1 : Vertical positions of maxillary central incisor in relation to the contralaterallyerupted tooth root length: V1- sector at the level of gingival third of the root; V2- sector at the level of middle third of the root; V3- sector at the level of apical third of the root.

The space available or created for the impacted central incisor in the dental arch was measured on the study models. The time (in months) of spontaneous eruption was registered as a time from surgical removal of the supernumerary tooth till visible emergence of impactedcentral incisor. The patients have been examined once per month over period of 30 months. After that period the impacted central incisors have been considered as spontaneously unerupted and treated by surgical re-opening and orthodontic traction.

\section{Data Management \& Statistical Analysis:}

The statistical analysis was performed using the Statistical Package for the Social Sciences for Windows (SPSS v. 10.0). For every variable the mean, standard deviation and minimum and maximum values were calculated. The tooth eruption time between groups was compared using the Student's t test for paired variables. Logistic regression analysis was used to assess the probability of eruption.

\section{Results}

The spontaneous eruption of impacted central incisors was registered in $30(68 \%)$ of cases after removal of the supernumerary tooth and the expansion of the dental arch. On the average time of spontaneous eruption for the study group was 10.9 months (from 4-29 months).Spontaneous eruption was recorded in $92 \%$ of cases in which impacted incisors initially were located in the sector V1, 93\% of cases in which impacted incisors were located in the sector V2 and onlyin $20 \%$ of cases in which impacted incisors were located in the 
sector V3. Differences in the spontaneous eruption time were found between the teeth groups with different initial vertical position (Table 1). Cox's regression analysis demonstrated that the probability of eruption in sector V 3 is 10 times lesser than sector V1 (Cox regression coefficient $=10.75$ ). The associations between the spontaneous eruption of an impacted tooth and its vertical position are presented in Figure 2.Also, results after comparison of bone density with no of erupted teeth and initial position of teeth are shown in Table 2 and 3 .

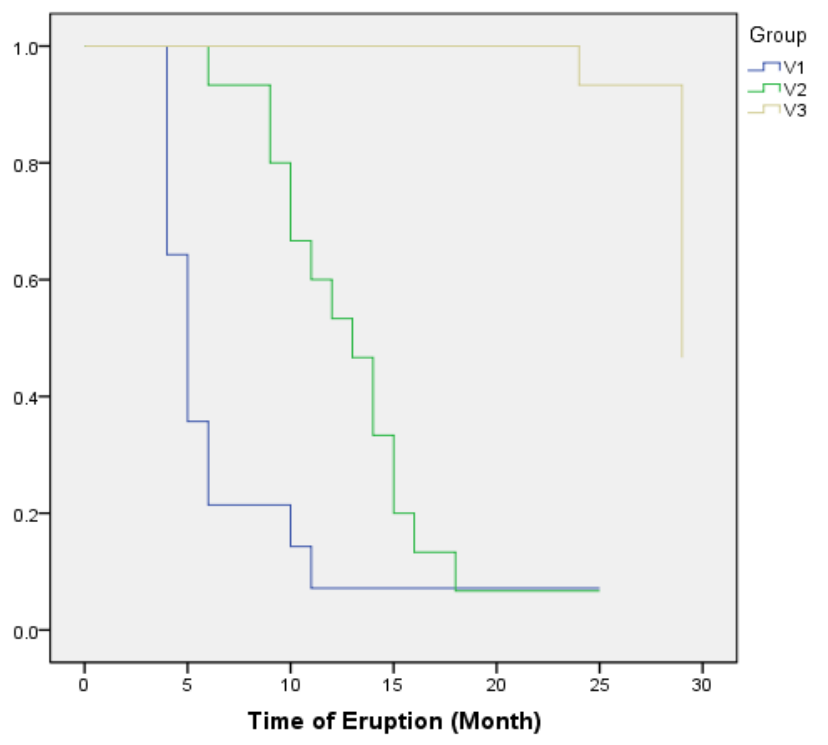

Figure 2: The association between the initial vertical position of an impacted tooth and the probability of its spontaneous eruption

Table 1: Timing of the spontaneous eruption of impacted central incisors

\begin{tabular}{|c|c|c|c|c|c|c|c|}
\hline \multirow{2}{*}{$\begin{array}{l}\text { Vertical position } \\
\text { of the impacted } \\
\text { teeth }\end{array}$} & \multirow[t]{2}{*}{$\begin{array}{l}\text { Number of } \\
\text { cases }\end{array}$} & \multirow[t]{2}{*}{$\begin{array}{l}\text { Number of } \\
\text { erupted teeth }\end{array}$} & \multicolumn{4}{|c|}{$\begin{array}{l}\text { Time of the spontaneous eruption } \\
\text { (Months) }\end{array}$} & \multirow[t]{2}{*}{ Level of significance } \\
\hline & & & Mean & SD & \begin{tabular}{l|l} 
& Max \\
\end{tabular} & Min & \\
\hline V1 & 14 & 13 & 5.62 & 2.2 & 11 & 4 & $\mathrm{p}_{12}=0.0001$ \\
\hline $\mathrm{V} 2$ & 15 & 14 & 12.2 & 3.2 & 18 & 6 & $\mathrm{p}_{13}=0.00001$ \\
\hline V3 & 15 & 03 & 27.3 & 2.8 & 29 & 24 & $\mathrm{p}_{23}=0.001$ \\
\hline Total & 44 & 30 & 10.9 & 6.9 & 29 & 4 & \\
\hline
\end{tabular}

Table 2: Comparison of initial position of tooth with bone density

\begin{tabular}{|l|l|l|l|l|}
\hline \multicolumn{3}{|c|}{} & \multicolumn{3}{|c|}{ Bone density } & \\
\cline { 3 - 4 } \multicolumn{3}{|c|}{ D2 } & D3 & Total \\
\hline \multirow{4}{*}{ Group } & V1 & 11 & 3 & 14 \\
& & & & \\
\cline { 2 - 5 } & V2 & 14 & 1 & 15 \\
\cline { 2 - 4 } & V3 & 14 & 1 & 15 \\
\hline Total & 39 & 5 & 44 \\
\hline
\end{tabular}

Table 3: Comparison of bone density and no of erupted teeth

\begin{tabular}{|c|c|c|c|c|}
\hline & \multicolumn{2}{|c|}{ Bone density } & \multirow[b]{2}{*}{ Total } \\
\hline & & D2 & D3 & \\
\hline \multirow[t]{2}{*}{ Erupted Teeth } & No & 12 & 1 & 13 \\
\hline & Yes & 27 & 4 & 31 \\
\hline Total & & 39 & 5 & 44 \\
\hline
\end{tabular}




\section{Discussion}

In our study we found that $68 \%$ of impacted incisors erupted spontaneously after removal of the supernumerary teeth, when it was sufficient space in the dental arch for the impacted tooth. The similar frequency of spontaneous eruption of impacted maxillary central incisors, varying from $54 \%$ to $64 \%$, has been reported by L. Mitchell and B. Witsenburg. Manson C. in his study found that even $72 \%$ of impacted teeth with incompletely formed roots erupted spontaneously. Percentage of spontaneously erupted teeth could be even higher, if we have observation period unlimited in time. But we had data of 30 months only. It might be because of request of patients to finish treatment in 2-4 years. The majority of impacted maxillary central incisor spontaneously erupts after removal of the supernumerary tooth but it takes significant period of time. The average spontaneous eruption time in our study was 17 months. $43 \%$ of the impacted central incisors spontaneously erupted during 1st year after removal of the supernumerary tooth. About $18 \%$ erupted during the second year of the observation. But even after 25 years of observation $31.8 \%$ of central incisors were still unerupted. Very similar results have been reported by L. Mitchell and W. Houston.A lot of factors can affect spontaneous eruption of impacted maxillary central incisors. Such factors as axial inclination of impacted teeth, lack of space in the dental arch, degree of root formation, relation to the adjacent teeth roots, initial vertical position of impaction affects process of spontaneous eruption. To avoid the bias of these different factors on the spontaneous eruption we conducted retrospective study using the criteria for case selection allowing us exclude all other factors except the initial vertical position of impacted maxillary central incisor. The results of our study demonstrate that spontaneous eruption of impacted central incisor is closely associated with its initial vertical position. Statistically significant difference in the spontaneous eruption time was detected between V1-V2 and V1-V3 groups. The impacted teeth located closer to the alveolar ridge (sector V1) mostly erupted spontaneously over the period of six months. But the impacted teeth that at the beginning of treatment were situated higher than $2 / 3$ of the adjacent central incisor root, spontaneously erupted only in three cases and it took $\sim 28$ months (i.e. 2 years) after the initiation of treatment. Taking into consideration these findings and experience, that as much as $90 \%$ of such teeth erupt in a wrong position, thus necessitating further orthodontic treatment, we suppose that in case of a high initial vertical position of the impacted maxillary central incisor conservative treatment is inexpedient. In such cases already during the first surgical intervention an attachment element should be fixed on the impacted tooth. H. Ibricevic also recommends the surgical-orthodontic treatment technique in cases when the impacted tooth is located in the middle part of the alveolus or higher.

Most tooth eruption anomalies may be avoided via timely diagnosis and application of treatmentpreventive measures. It is reported that only $54 \%$ of mesiodens cases are diagnosed at the aged of 5-9 years, i.e. at the time when the eruption of permanent incisors should start. So, early diagnostics of the maxillary central incisor impactions and surgical removal of supernumerary tooth as well as adequate space for it maintained in the dental arch may facilitate spontaneous eruption of the impacted maxillary central incisors.

\section{Conclusions}

1. The study found that impacted maxillary central incisors spontaneously erupt in $68 \%$ of cases after obstruction elimination by the removal of supernumerary teeth.

2. The average time of the spontaneous eruption of impacted maxillary central incisors after the supernumerary teeth removal was 17 months.

3. Statistically significant differences in the spontaneous eruption time were found between the groups with different initial vertical position of theimpacted central maxillary incisor.

4. Maxillary central incisor impacted at the projection level of the apical third of the contralateral completely erupted central maxillary incisor root, should be treated by the surgical-orthodontic approach, because spontaneous eruption is unlikely to expect.

[1]. Snow K. Articulatory Proficiency in Relation to Certain Dental Abnormalities. Journal of Speech and Hearing Disorders 1961; 26: 209-12.

[2]. Shaw WC, O’Brien KD, Richmond S, Brook P. Quality control in orthodontics: risk/benefit considerations. Br Dent J1991; 170: 33-37.

[3]. Mac Phee CG. The incidence of erupted supernumerary teeth in consecutive series of 4000 school children. Br Dent J1935; 58: 5960.

[4]. Huber KL, Suri L, Taneja P. Eruption disturbances of the maxillary incisors: a literature review 1.J ClinPediatr Dent. 2008;32(3):221-230.

[5]. Smailiene D, Sidlauskas A, Bucinskiene J. Impaction of the central maxillary incisor associated with supernumerary teeth: initial position and spontaneous eruption timing. Stomatologija. 2006;8(4):103-107.

[6]. Jones JW. A Medico-legal Review of Some Current UK Guidelines in Orthodontics: A personal View. J Orthod. 1999;26:307324.Cons NC, Jenny J, Kohout FJ. DAI: the dental aesthetic index. Iowa: College of Dentistry, University of Iowa; 1986.

[7]. Becker A. The orthodontic treatment of impacted teeth. Mosby; 1998. p. 53-85.

[8]. Gregg TA, Kinirons MJ. The effect of the position and orientation of uneruptedpremaxillary supernumerary teeth on eruption and displacement of permanent incisors. Int J Paediatr Dent 1991; 1: 3-7 
[9]. Rajab LD, Hamdan M. Supernumerary teeth: review of the literature and a survey of 152 cases. Int J Paediatr Dent 2002: 12(4) 244 $-54$.

[10]. Oliver RG, Moxham BJ. Malformations of teeth. CurrPediatr 1999; 9:257-61

[11]. Acikgöz G, Acikgöz A, Keskiner I, Türk T, Otan F. Aggres- sive periodontitis with supernumerary teeth: a retrospec- tive study. $J$ Periodontol 2004; 75: 1458- 60.

[12]. Roberts-Hary D, Sandy J. Orthodontics. Part 10: Impacted teeth. Br Dent J 2004; 196 (6): 319-27.

[13]. Oliver R, Hodges ChGL. Delayed eruption of a maxillary central incisor associated with an odontome: report of case. $J$ Dent Child 1988; 55(5): 368-71.

[14]. Crawford LB. Impacted maxillary central incisor in mixed dentition treatment. Am J OrthodDentofacOrthop 1997; $112(1): 1-7$.

[15]. Garvey M.T., Barry H.J., Blake M. Supernumerary teeth - an overview of classification, diagnosis and management. J Canad Dent Assoc 1999; 65: 612-6.

[16]. Mitchell L., Bennett T.G. Supernumerary teeth causing de- layed eruption. Br J Orthod1992; 19: 41-6.

[17]. Witsenburg B, Boering G, Witsenburg B. Eruption of permanent impacted incisor after removal of supernumeraryteeth. Int J Oral Surg 1981: 10: 423-31. 12 .

[18]. Mason C., Azam N., Holt R.D., Rule D.C. A retrospectivestudy of unerupted maxillary incisors associated with su- pernumerary teeth. Br J Oral MaxillofacSurg 2000; 38: 62- 5.

[19]. Becker A. Early treatment for impacted maxillary incisors. Am J OrthodDentofacOrthop 2002; 121( 6): 586

[20]. Becker A, Brin I, Ben- Bassat Y, Zilberman Y, Chaushu S. Closed- eruption surgical technique for impacted maxillary incisors: a postorthodontic periodontal evaluation. Am J OrthodDentofacOrthop 2002; 122(1): 9-14.

[21]. Kajiyama K, Kai H. Esthetic management of an unerupted maxillary central incisor with a closed eruption technique. Am $J$ OrthodDentofacOrthop 2000; 118(2): 224-8.

[22]. Cons NC, Jenny J, Kohout FJ. DAI: the dental aesthetic index. Iowa: College of Dentistry, University of Iowa; 1986.

[23]. Snow K. Articulatory Proficiency in Relation to Certain Dental Abnormalities. Journal of Speech and Hearing Disorders1961; 26: 209-12.

[24]. Bankson NW, Byrne MC. The RelationshipBetween Missing Teeth and Selected Consonant Sounds. Journal of Speech and Hearing Disorders 1962; 27: 341-48.

[25]. Weinberg B. A cephalometric study of normal and defective -s- articulation and variations in incisor dentition. $J$ Speech Hear Res 1968; 11: 288-300.

[26]. Shaw WC, O’Brien KD, Richmond S, Brook P. Quality control in orthodontics: risk/benefit considerations. Br Dent J1991; 170: 33-37.

[27]. Hitchen AD. The impacted maxillary incisor. Dent Pract Dent Rec1970; 20: 423-33

[28]. Mac Phee CG. The incidence of erupted supernumerary teeth in consecutive series of 4000 school children. Br Dent J1935; 58: 5960 .

[29]. Di Biase DD. Midline supernumeries and eruption of maxillary central incisors. Transactions of the BSSO1968-1969; 83-88.

[30]. Moyers RE, van der Linden FP, Riolo ML, McNamara Jr JA. Standards of human occlusal development. Ann Arbor, Michigan: Centre for Human Growth and Development, University of Michigan; 1976

[31]. Armstrong C, Johnston C, Burden D, Stevenson M. Localizing ectopic maxillary canines - horizontal or vertical parallax? Eur J Orthod2003; 25: 585-89.

[32]. Brook AH. Dental anomalies of number, form and size: their prevalence in British schoolchildren. J IntAssoc Dent Child1974, 5: $37-53$.

[33]. Isaacson KG, Thom AR, Horner K, Whaites E. Orthodontic radiographs - guidelines, 3rd edn. London: British Orthodontic Society; 2008 .

[34]. Di Biase DD. The effects of variations in tooth morphology and position on eruption. Dent Pract Dent Rec 1971; 22: 95-108

[35]. Munns D. Unerupteduncisors. Br J Orthod 1981; 8: 39-42.

[36]. Leyland L, Batra P, Wong F, Llewelyn R. A retrospective evaluation of the eruption of impacted permanent incisors after extraction of supernumerary teeth. J ClinPediat Dent2006; 30: 225-31.

[37]. Betts A, Camilleri G. A review of 47 cases of unerupted maxillary incisors. Int J Paediatr Dent 1999; 9: $285-92$.

[38]. Foster TD, Taylor GS. Characteristics of supernumerary teeth in the upper central incisorregion. Dent Pract Dent Rec1969; 20: 812. 18 .

[39]. Katz RW. An analysis of compound and complexodontomas. ASDC J Dent Child1989; 56: 445-49.

[40]. Yeung K, Cheung R, Tsang M. Compoundodontoma associated with an unerupted and dilacerated maxillary primary central incisor in a young patient. Int J Paediatr Dent2003; 13: 208-12.

[41]. Kajiyama K, Kai H. Esthetic management of an unerupted maxillary central incisor with a closed eruption technique. Am J Orthod and DentofacialOrthop2000; 118: 224-28.

[42]. Mitchell L, Bennett TG. Supernumerary teeth causing delayed eruption - a retrospective study. Br J Orthod1992; 19: 41-46.

[43]. Witsenberg B, Boering G. Eruption of impacted permanent incisors after removal of supernumerary teeth. Int J Oral Surg 1981; 10: 423-31.

[44]. Bryan RA, Cole BO, Welbury RR. Retrospective analysis of factors influencing the eruption of delayed permanent incisors after supernumerary tooth removal. Eur J Paediatr Dent 2005; 6: 84-89.

[45]. Ashkenazi M, Greenberg BP, Chodik G, Rakocz M. Postoperative prognosis of unerupted teeth after removal of supernumerary teeth or odontomas. Am J OrthodDentofacialOrthop 2007; 131: 614-19.

[46]. Vermette ME, Kokich VG, Kennedy DB. Uncovering labially impacted teeth: apically positioned flap and closed-eruption techniques. Angle Orthod1995; 65: 23-32.

[47]. Jorkjend L, Skoglund LA. Effect of non-eugenol and eugenol-containing periodontal dressings on the incidence and severity of pain after periodontal soft tissue surgery. J ClinPeriodontol1990; 17: 341-44.

[48]. Sanz M, Newman MG, Anderson L et al. Clinical enhancement of post-peripodontal surgical therapy by a 0.12\% chlorhexidinegluconatemouthrinse. J Periodontol1989; 60: 570-76.

[49]. Becker A, Shpack N, Shteyer A. Attachment bonding to impacted teeth at the time of surgical exposure. Eur J Orthod1996; 18: 457-63.

[50]. Oliver RG, Hardy P. Practical and theoreticalaspects of a method of orthodontic traction to unerupted teeth illustrated by three cases Br J Orthod 1986; 13: 229-36.

[51]. Sandler PJ, Meghji S, Murray AM et al. Magnets and orthodontics. Br J Orthod1989; 16: 243-49.

[52]. Profitt W. Contemporary Orthodontics. St Louis: Mosby1992.

[53]. Foley J. Surgical removal of supernumerary teeth and the fate of incisor eruption. Eur J Paediatr Dent2004; 5: 35-40. 
[54]. Noar JH, Gaukroger MJ. Customized metal coping for elastic traction of an ectopic maxillary central incisor. J ClinOrthod2000; 34: 585-89.

[55]. Uematsu S, Uematsu T, Furusawa K et al. Orthodontic treatment of an impacted dilacerated maxillary central incisor combined with surgical exposure and apicoectomy. Angle Orthod2004; 74: 132-36.

[56]. Becker A, Brin I, Ben-Bassat Y et al. Closed- eruption surgical technique for impacted maxillary incisors: a postorthodontic periodontal evaluation. Am J OrthodDentofacialOrthop2002; 122: 9-14.

[57]. Bayram M, Ozer M, Sener I. Bilaterally impacted maxillary central incisors: surgical exposure and orthodontic treatment: a case report. J Contemp Dent Pract2006, 7: 98-105.

[58]. Stewart DJ. Dilacerate unerupted maxillary central incisors. Br Dent J1978; 145: 229-33.

[59]. Nashashibi IA. Orthodontic movement of a palatally displaced, dilacerated, unerupted maxillary central incisor. J Pedod1986; 11 : 83-90.

[60]. Sandler PJ, Reed RT. Treatment of a dilacerated incisor. J ClinOrthod1988; 22: 374-76. 